\title{
Activity Energy Expenditure in Youth: Sex, Age, and Body Size Patterns
}

\author{
Jung-Min Lee, Pedro F. Saint-Maurice, Youngwon Kim, Glenn A. Gaesser, and Gregory Welk
}

\begin{abstract}
Background: The assessment of physical activity (PA) and energy expenditure (EE) in youth is complicated by inherent variability in growth and maturation during childhood and adolescence. This study provides descriptive summaries of the EE of a diverse range of activities in children ages 7 to 13. Methods: A sample of 1057 - to 13-year-old children (boys: 57\%, girls: 43\%, and Age: $9.9 \pm 1.9$ ) performed a series of 12 activities from a pool of 24 activities while being monitored with an indirect calorimetry system. Results: Across physical activities, averages of $\mathrm{VO}_{2} \mathrm{ml} \cdot \mathrm{kg} \cdot \mathrm{min}^{-1}, \mathrm{VO}_{2} \mathrm{~L} \cdot \mathrm{min}^{-1}$, EE, and METs ranged from 3.3 to $53.7 \mathrm{ml} \cdot \mathrm{kg} \cdot \mathrm{min}^{-1}$, from 0.15 to $3.2 \mathrm{~L} \cdot \mathrm{min}^{-1}$, from 0.7 to $15.9 \mathrm{kcal} \cdot \mathrm{min}^{-1}, 1.5 \mathrm{MET}$ to $7.8 \mathrm{MET}$, respectively. Conclusions: The energy costs of the activities varied by age, sex, and BMI status reinforcing the need to consider adjustments when examining the relative intensity of PA in youth.
\end{abstract}

Keywords: physical activity, children

Obtaining accurate assessments of PA and energy expenditure (EE) is challenging for all populations but especially for children and adolescents due to the inherent variability due to growth and maturation. In 2008, Ridley at al developed the Compendium of Energy Expenditure for Youth (CEEY) to facilitate standardized reporting and evaluation of $\mathrm{PA}$ and $\mathrm{EE}$ in youth. ${ }^{1}$ The database included Metabolic Equivalent Tasks (METs) values for 244 commonly performed activities by youth in children ages 6 to 18 years and promoted the debate around adult- vs. child-derived METs. To date, the CEEY has been widely used in the field to estimate EE levels in youth; however, it is important to expand these values and overcome the limitations of adult-derived METs. The purposes of this study were to (1) report EE values in children while performing a variety of activities which will contribute to the refinement of the existent PA compendium for youth; and (2) reinforce the need for a refined child compendium by examining the impact of age, sex, and body size on the energy cost (ie, METs) associated with different activities.

\section{Methods}

Data for the current study were obtained from a large calibration study focused on evaluating the validity of different accelerometrybased activity monitors (R01 HL091006). Outcomes from the study have been reported in other papers but brief descriptions of the methods are provided to explain the specific procedures used with the indirect calorimetry assessments since that is the focus of the present paper.

Lee (jungminlee@unomaha.edu) is with the Dept of School of Health, Physical Education, and Recreation, University of Nebraska at Omaha. Saint-Maurice is with the Dept of Kinesiology, Iowa State University, Kim is with the MRC Epidemiology Unit, University of Cambridge School of Clinical Medicine. Gaesser is with the School of Nutrition and Health Promotion, Arizona State University. Welk is the Dept of Kinesiology, Iowa State University.

\section{Participants}

A total of 105 children (ages 7 to 13 years) participated in the study ( 60 boys and 45 girls; mean age $9.9 \pm 1.9$ years; mean weight 39.4 $\pm 14.9 \mathrm{~kg}$; mean height $146.4 \pm 13.9 \mathrm{~cm} ; 91.2 \%$ Caucasian; $9.8 \%$ overweight; $6.9 \%$ obese). Before beginning the project, participants provided assent and parents/guardians provided informed consent. The study was approved by the Institutional Review Board of Iowa State University.

\section{Activities}

Each participant reported to the laboratory and completed a set of 12 different free-living activities ( 5 minutes each) in a gym while being monitored with a portable indirect calorimetry system). The 12 activities were randomly assigned from a pool of 24 activities of varying intensity to simulate real-world conditions. A 1-min resting interval was included between each of the activities, resulting in a total session duration of 71 minutes. All activities were performed in a supervised research setting to make sure that children engaged in the activities at the assigned intensity (ie, sedentary, light, moderate to vigorous) and for the appropriate duration.

\section{Measurements}

EE was assessed using a lightweight (950 g), portable indirect calorimetry system (Oxycon Mobile (OM); Carefusion, San Diego, CA, USA). Before each trial, flow-volume and gas calibrations were performed according to manufacturer guidelines. Breath-by-breath measures of pulmonary ventilation and gas exchange were used to calculate oxygen uptake $\mathrm{VO}_{2}\left(\mathrm{ml} \cdot \mathrm{kg} \cdot \mathrm{min}^{-1}\right), \mathrm{EE}\left(\mathrm{kcal} \cdot \mathrm{min}^{-1}\right)$, and MET values. To optimize chances of obtaining steady-state values, only data collected during the 3rd and 4th minute of each activity were used for calculations.

\section{Analysis}

Descriptive statistics (mean, standard deviation (SD), range) for the measured $\mathrm{VO}_{2}\left(\mathrm{ml} \cdot \mathrm{kg} \cdot \mathrm{min}^{-1}\right.$ and $\left.\mathrm{L} \cdot \mathrm{min}^{-1}\right) \mathrm{EE}\left(\mathrm{Kcal} \cdot \mathrm{min}^{-1}\right)$, and 
METs were calculated by sex, age groups (ie, 7 to 9 years and 10 to 13 years), and BMI classes (ie, normal weight and overweight/ obese). METs were computed by dividing the activity $\mathrm{VO}_{2}$ (ie, $\mathrm{ml} \cdot \mathrm{kg} \cdot \mathrm{min}^{-1}$ ) by the participant's resting metabolic rate (REE; ie, $\mathrm{ml} \cdot \mathrm{kg} \cdot \mathrm{min}^{-1}$ ) estimated utilizing the age- and sex-specific Schofield equation (ie, Youth MET and herein referred to as METy). ${ }^{2}$ A three-way analysis of variance was first computed using SAS Proc Mixed (with t distribution) to examine the effect of sex, age group, and BMI class on estimated MET values aggregated across all activities. Interactions were limited to two-way effects for all possible comparisons (eg, BMI class $\times$ Sex). We found no statistically significant interactions effect and therefore limited the ANOVA analysis to main effects to facilitate interpretation. These analyses were followed by identical ANOVA models with the 3 factors, stratified by each of the 24 activities. This allowed for the examination of differential effects between the factors and MET values depending on the activity type or intensity. To account for multiple comparisons, $P$-values for these analyses were considered statistically meaningful if $<0.01$. All statistical analyses were performed using the SPSS program (IBM SPSS, version 22.0, Chicago, IL, USA) and the statistical significance was set at $\alpha=.01$.

\section{Results}

Boys were of the same height as girls but were heavier and had higher BMI percentiles. Predicted REE was similar between boys and girls $\left(\mathrm{REE}_{\text {boys }}=4.1 \pm 2.2 \mathrm{ml} \cdot \mathrm{kg} \cdot \mathrm{min}^{-1}\right.$ and $\mathrm{REE}_{\text {girls }}=4.1 \pm 2.2$ $\left.\mathrm{ml} \cdot \mathrm{kg} \cdot \mathrm{min}^{-1}\right)$. Older age youth were taller, heavier, and had higher $\operatorname{REE}\left(\mathrm{REE}_{7-9 \mathrm{yrs}}=3.9 \pm 1.9 \mathrm{ml} \cdot \mathrm{kg} \cdot \mathrm{min}^{-1}\right.$ and $\mathrm{REE}_{10-13 \mathrm{yrs}}=4.2 \pm 2.5$ $\left.\mathrm{ml} \cdot \mathrm{kg} \cdot \mathrm{min}^{-1}\right)$, but had slightly lower BMI percentiles. Comparisons by body size (ie, BMI) resulted in lower REE for the overweight/ obese children $\left(\mathrm{REE}_{\mathrm{NW}}=5.0 \pm 0.6 \mathrm{ml} \cdot \mathrm{kg} \cdot \mathrm{min}^{-1}=\right.$ and $\mathrm{REE}_{\mathrm{OW}}=4.4$ $\left.\pm 0.7 \mathrm{ml} \cdot \mathrm{kg} \cdot \mathrm{min}^{-1}\right)($ Table 1$)$.

The average EE values for the various sedentary activities ranged from $7.3 \mathrm{ml} \cdot \mathrm{kg} \cdot \mathrm{min}^{-1}$ (ie, sitting and watching TV) to 8.5 $\mathrm{ml} \cdot \mathrm{kg} \cdot \mathrm{min}^{-1}$ (ie, sitting and typing at a computer), or 1.5 to $1.8 \mathrm{METs}$. Light activities elicited EE values that ranged from $14.5 \mathrm{ml} \cdot \mathrm{kg} \cdot \mathrm{min}^{-1}$ (ie, slow walking) to $18.5 \mathrm{ml} \cdot \mathrm{kg} \cdot \mathrm{min}^{-1}$ (ie, playing catch with a ball) and these were equivalent to a range of 3.0 to 3.8 METs. For moderate-to-vigorous physical activities (MVPA). EE ranged from $15.0 \mathrm{ml} \cdot \mathrm{kg} \cdot \mathrm{min}^{-1}$ (ie, hand weight exercises) to $37.3 \mathrm{ml} \cdot \mathrm{kg} \cdot \mathrm{min}^{-1}$ (ie, jogging at the fast pace), or 3.1 to 7.8 METs (Table 2).

Three-way ANOVA revealed a significant main effect for age group $[t(1258)=-2.67, P=.007]$ and showed that the average
MET values were greater among older participants $\left(\mathrm{METs}_{7-9 \mathrm{yrs}}=\right.$ $3.91 \pm 0.11$ vs. METs $\left._{10-13 \mathrm{yrs}}=4.23 \pm 0.09\right)$. There were no main effects for sex $[t(1258)=0.00, P=.999]$ or BMI status $[t(1258)$ $=-0.14, P=.886]$. Follow-up examination of variability in MET values associated with sex, age, and BMI status was conducted for each of the activities revealing higher MET values among older participants when jogging at either slow $\left[\mathrm{Mean}_{\text {diff }}=+1.08 \pm 0.39\right.$ METs; $t(72)=2.80, P=.007]$ or fast pace $\left[\mathrm{Mean}_{\text {diff }}=+1.43 \pm 0.34\right.$ METs; $t(85)=4.20, P<.001]$. MET values were also higher for girls when typing at a computer $\left[\mathrm{Mean}_{\text {diff }}=+0.37 \pm 0.11\right.$ METs; $t(59)=3.28, P=.001]$.

Additional analyses were performed to verify the stead-state level of the activity intensity and revealed high intraclass correlations coefficient (ICC) values across each of the 5-min activity trails regardless of whether they were preceded by vigorous or sedentary intensity activities (mean ICC $=0.87 ; 88 \%$ of the activities had an ICC $>0.80)$.

\section{Discussion}

This study builds on the need to develop a child-specific compendium of physical activities to facilitate the transition away from the classical approach of classifying activity intensity using METs derived from adult values of REE (ie, $3.5 \mathrm{ml} \cdot \mathrm{kg} \cdot \mathrm{min}$ ). We have previously reported on this need using this same dataset ${ }^{3}$ but our previous work was limited to implications associated with the assessment of sedentary activities. The present analyses provided a more systematic evaluation of the potential moderating impact of sex, age, and body size on EE values from an array of simulated free-living activities. We focused particularly on EE when expressed in METs since this metric has proven to be very useful for standardization of energy cost associated with different activities. ${ }^{4}$ The results revealed no effect of body size or sex (with the exception of typing at a computer) on METy, but there were some meaningful age differences when participants engaged in jogging (slow and fast pace). The similar patterns in METs were likely a result of adjusting MET values to each individual child REE.

We therefore conducted supplemental analyses to directly examine the impact of using adult-METs (ie, $3.5 \mathrm{ml} \cdot \mathrm{kg} \cdot \mathrm{min}^{-1}$ ) and specifically examined if BMI was likely to lead to differences in EE when adult-METs are used instead. We computed identical ANOVA models (sex, age, and BMI) stratified by activity but had a particular interest in BMI status. Contrary to our previous results, we found significant differences for all the 3 factors in at least 1 activity

Table 1 Descriptive Characteristics of the Participants

\begin{tabular}{|c|c|c|c|c|c|c|c|}
\hline & $\mathrm{n}$ & Age (y) & Height (cm) & Weight (kg) & BMI $\left(\mathbf{k g} \cdot \mathrm{m}^{-2}\right)$ & $\begin{array}{c}\text { BMI } \\
\text { (percentile) }\end{array}$ & $\begin{array}{c}\text { REE } \\
\left(\mathrm{ml} \cdot \mathrm{kg} \cdot \mathrm{min}^{-1}\right)\end{array}$ \\
\hline Total & 105 & $9.9 \pm 1.9$ & $146.4 \pm 13.9$ & $39.4 \pm 14.9$ & $17.7 \pm 3.8$ & $50.8 \pm 28.9$ & $4.1 \pm 2.1$ \\
\hline Girls & 45 & $9.9 \pm 1.8$ & $146.3 \pm 12.3$ & $37.4 \pm 10.1$ & $17.2 \pm 2.6$ & $48.5 \pm 27.6$ & $4.1 \pm 2.0$ \\
\hline Boys & 60 & $10.0 \pm 2.0$ & $146.7 \pm 14.9$ & $39.4 \pm 14.9$ & $17.9 \pm 4.4$ & $52.8 \pm 29.5$ & $4.1 \pm 2.2$ \\
\hline $7-9 y$ & $43(21 \mathrm{~F}, 22 \mathrm{M})$ & $8.1 \pm 0.9$ & $135.5 \pm 7.8$ & $30.4 \pm 5.4$ & $16.5 \pm 1.7$ & $54.5 \pm 26.8$ & $3.9 \pm 1.9$ \\
\hline $10-13 \mathrm{y}$ & $62(23 \mathrm{~F}, 39 \mathrm{M})$ & $11.4 \pm 1.1$ & $154.4 \pm 11.7$ & $44.7 \pm 13.8$ & $18.5 \pm 4.5$ & $48.3 \pm 29.9$ & $4.2 \pm 2.5$ \\
\hline Normal weight & 85 & $8.1 \pm 0.9$ & $146.1 \pm 13.0$ & $35.5 \pm 8.3$ & $16.4 \pm 1.5$ & $41.1 \pm 22.8$ & $5.0 \pm 0.6$ \\
\hline $\begin{array}{l}\text { Overweight/ } \\
\text { obese }\end{array}$ & 20 & $10.1 \pm 2.1$ & $148.0 \pm 17.0$ & $51.8 \pm 19.7$ & $23.0 \pm 5.3$ & $92.1 \pm 5.3$ & $4.4 \pm 0.7$ \\
\hline
\end{tabular}

Abbreviations: F, female; M, male; y, years. 


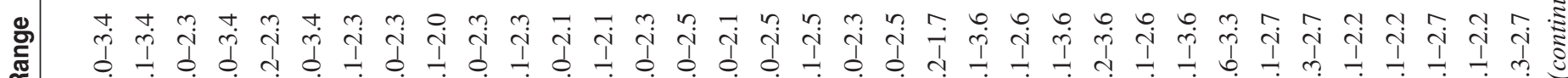

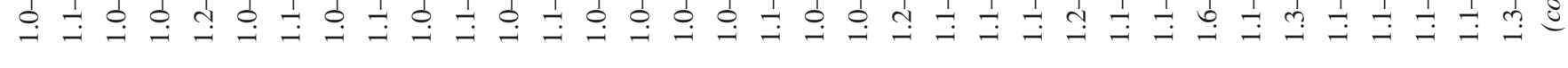

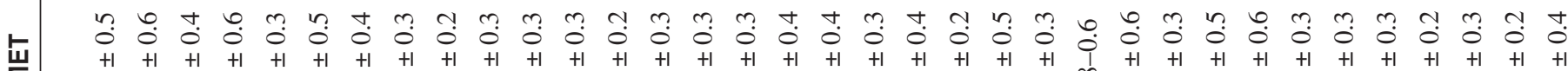

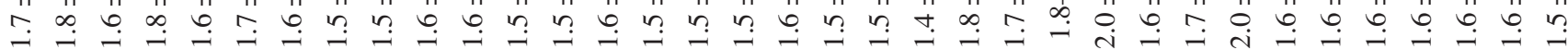

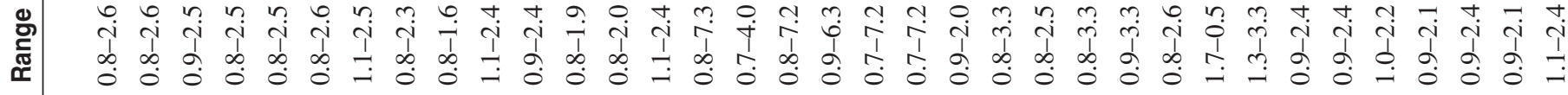

ț

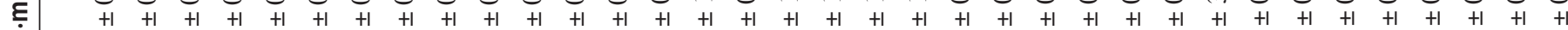

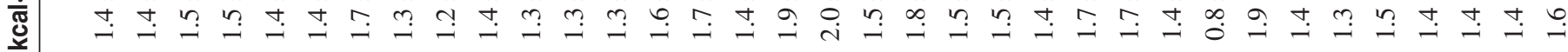

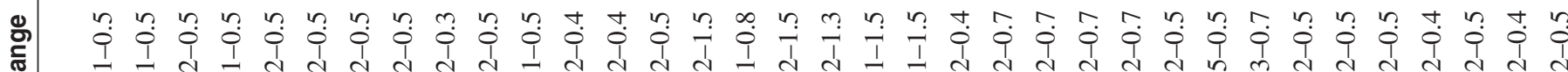

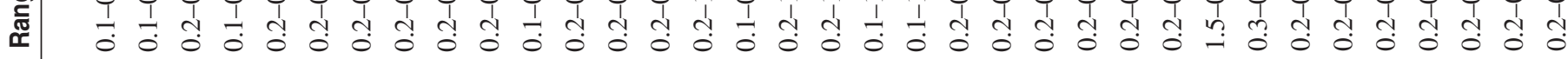

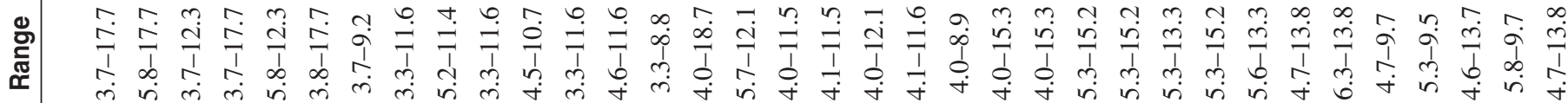

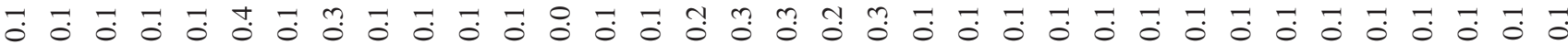
$\begin{array}{lllllllllllllllllllllllllllllllllllllllllllll}+1 & +1 & +1 & +1 & +1 & +1 & +1 & +1 & +1 & +1 & +1 & +1 & +1 & +1 & +1 & +1 & +1 & +1 & +1 & +1 & +1 & +1 & +1 & +1 & +1 & +1 & +1 & +1 & +1 & +1 & +1 & +1 & +1 & +1 & +1\end{array}$

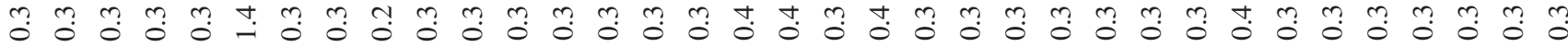

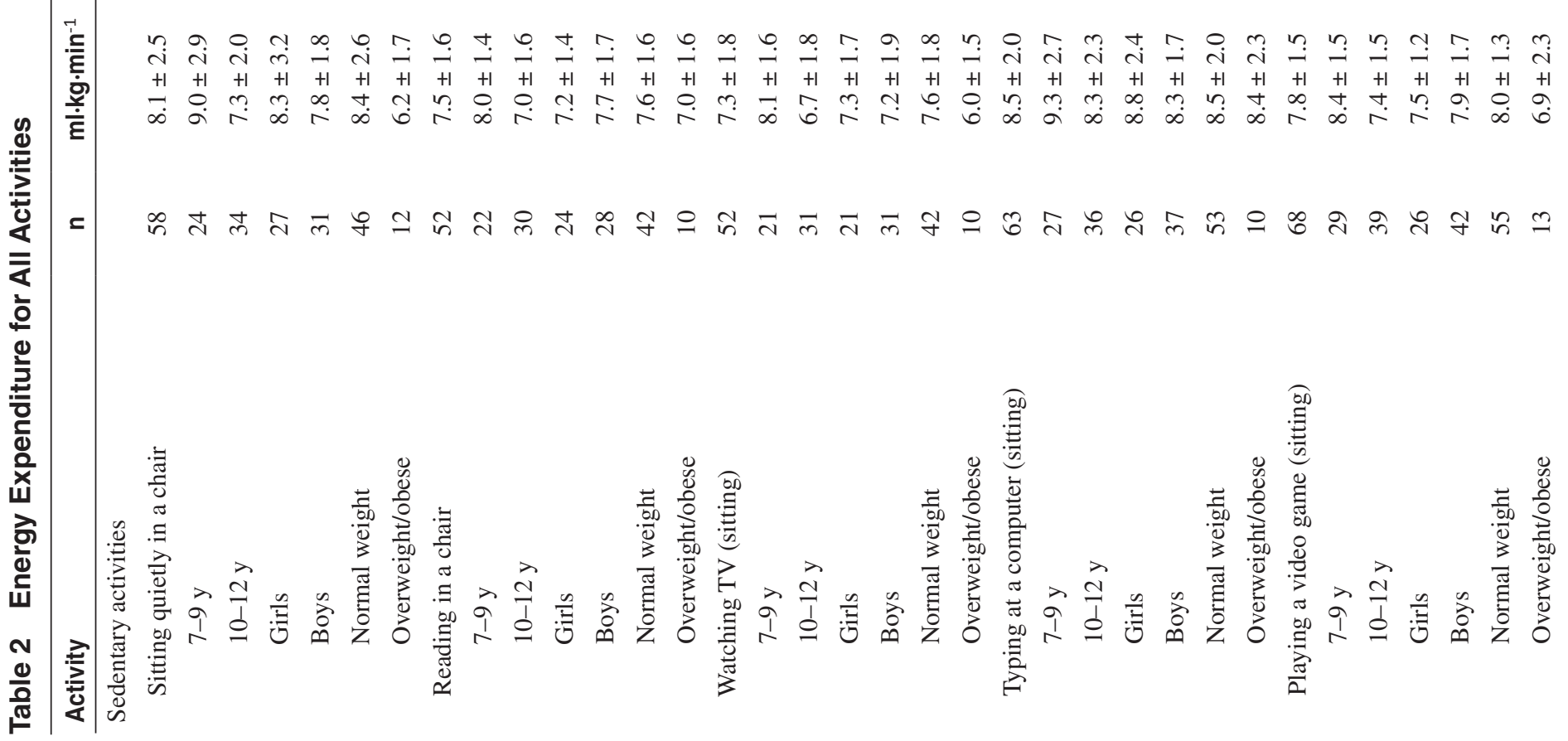




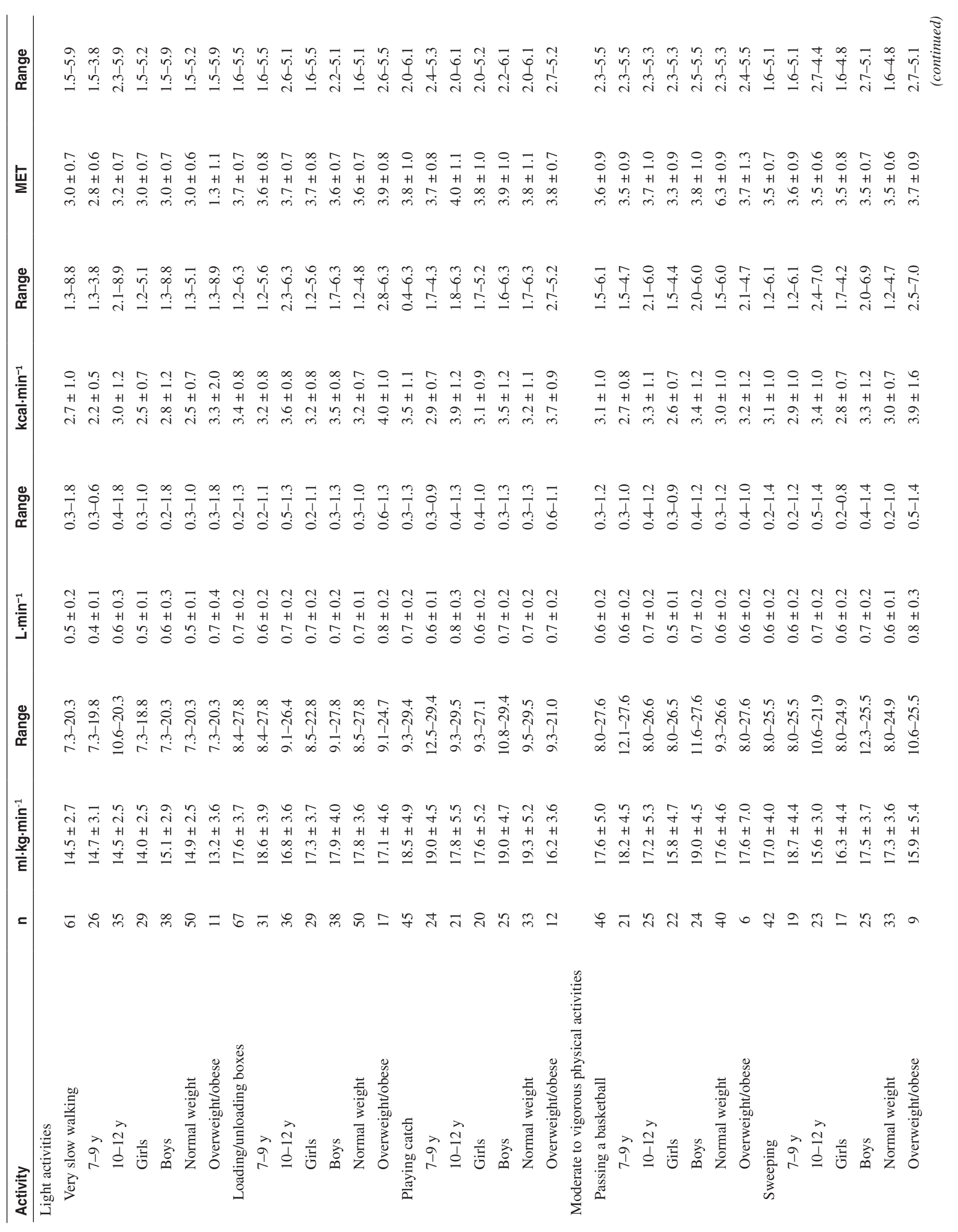


$\otimes \because$

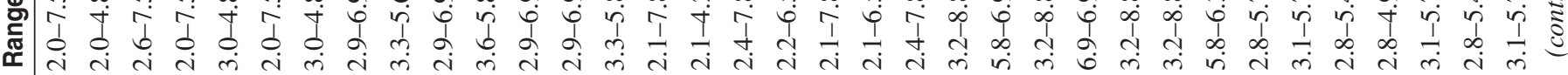

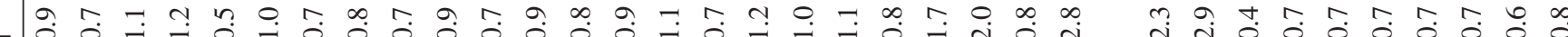

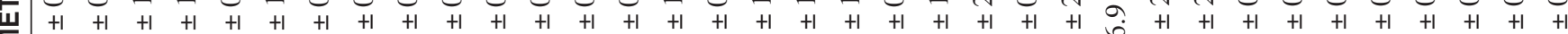

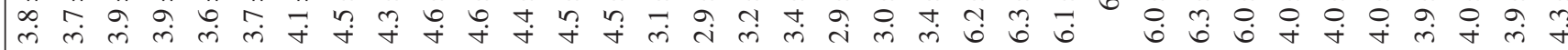

-

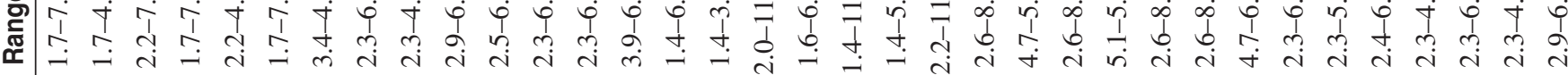

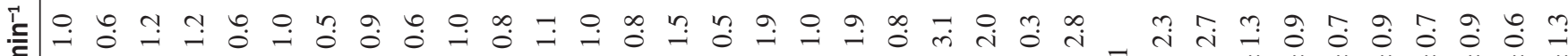

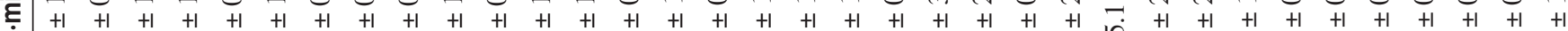

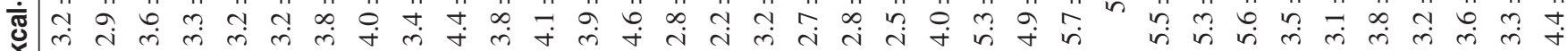

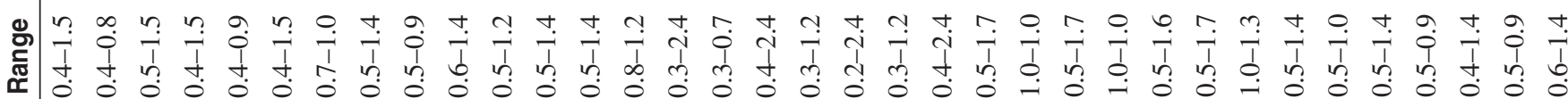

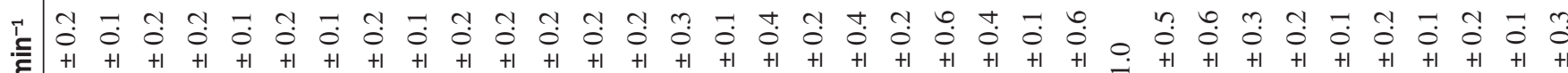

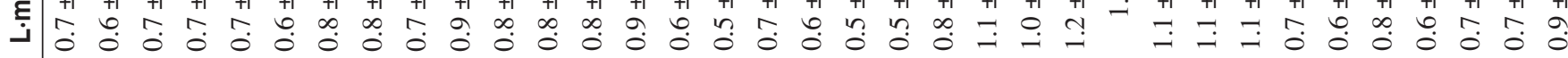

ฆ ๘

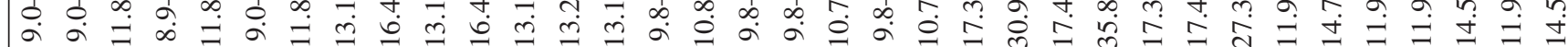

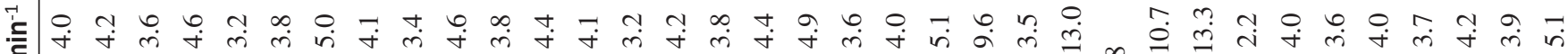

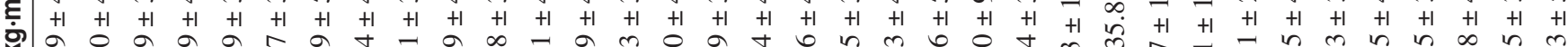

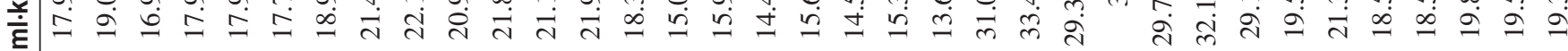

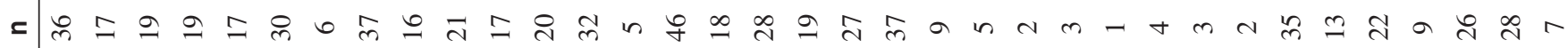




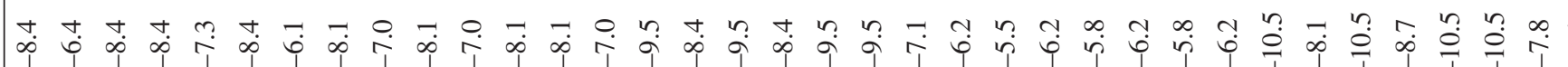

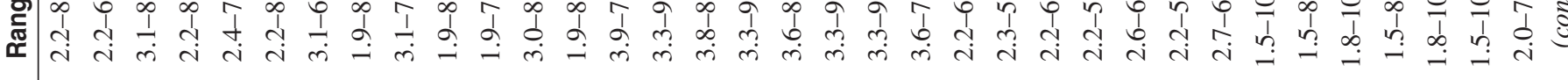

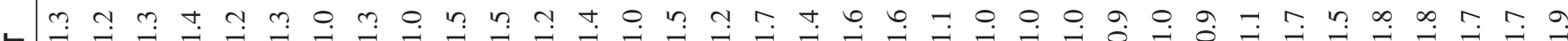

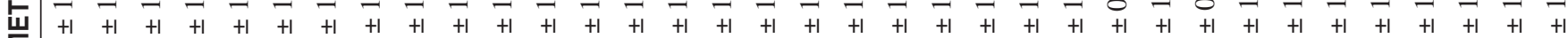

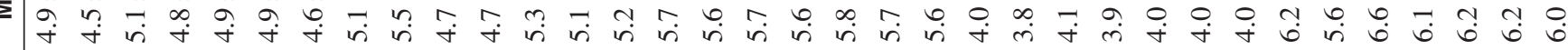

\&

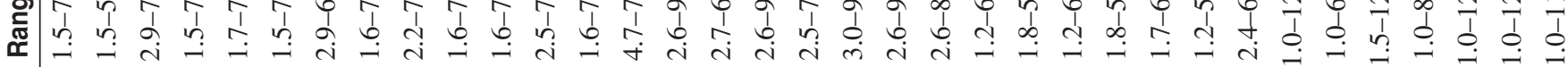

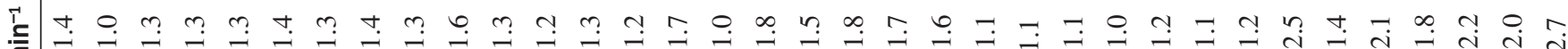

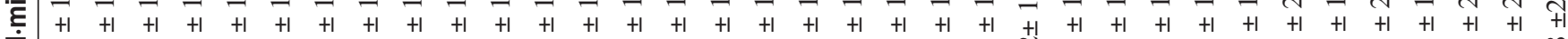

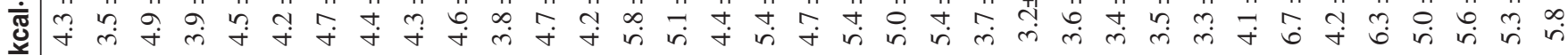

बำ ॠ

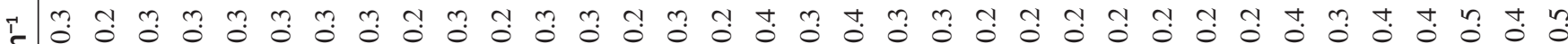

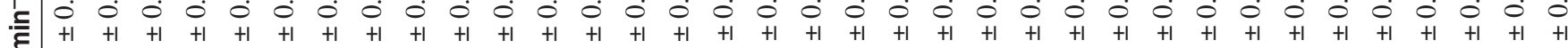

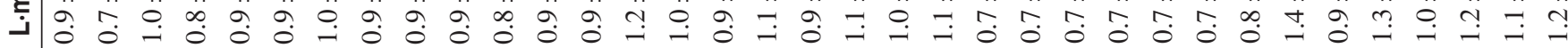

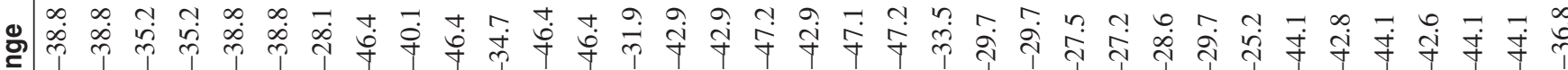

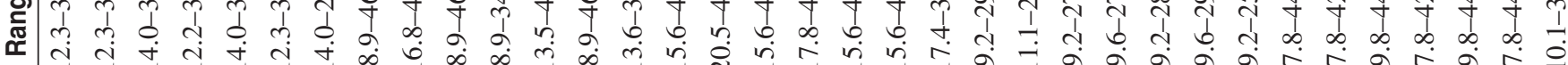

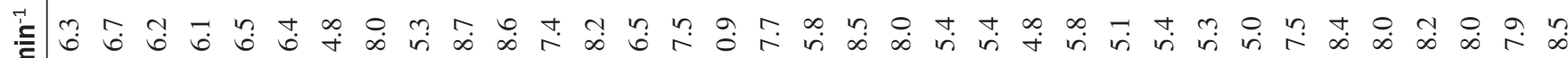

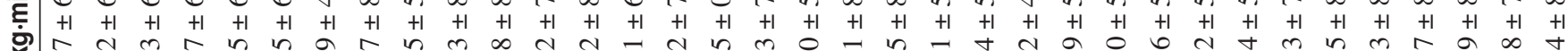

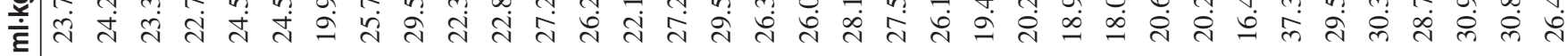

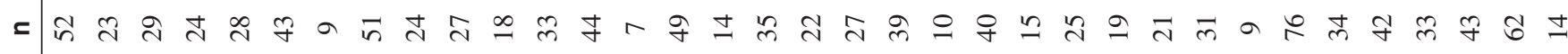

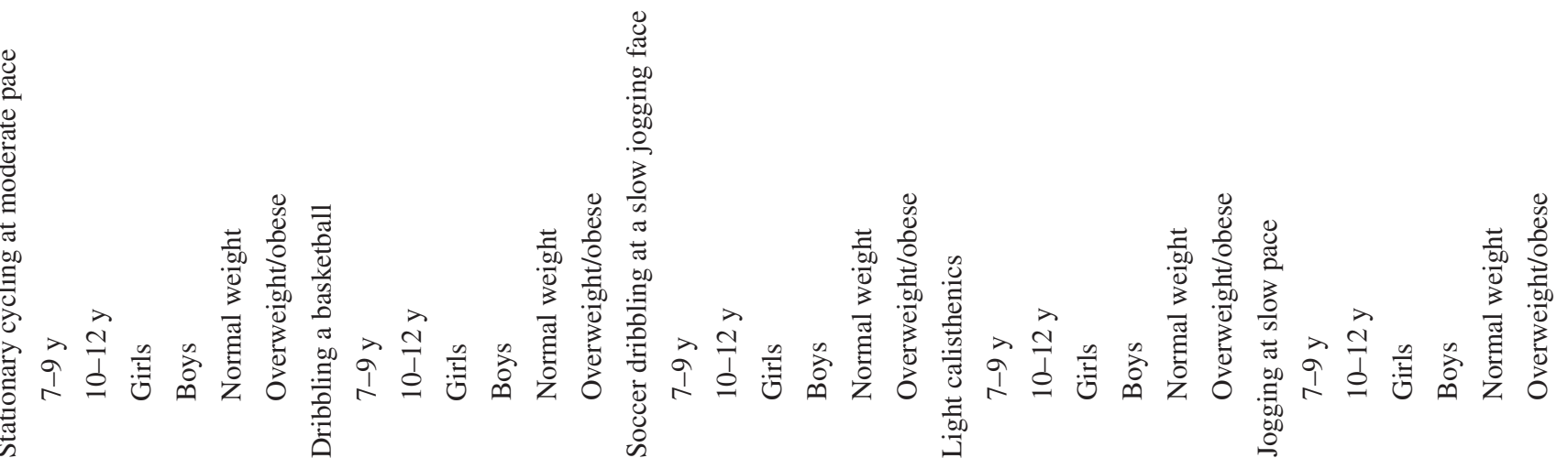




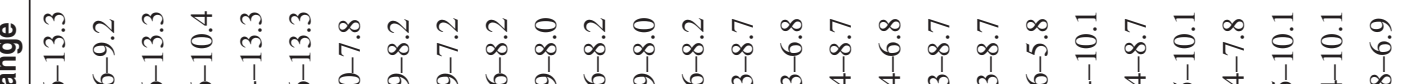

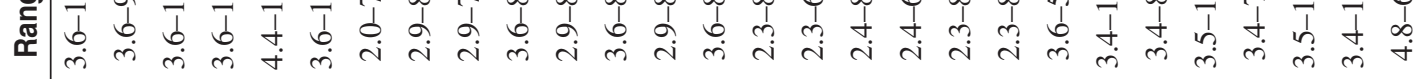

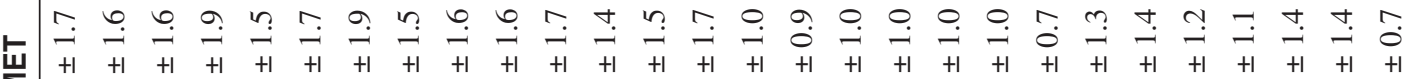

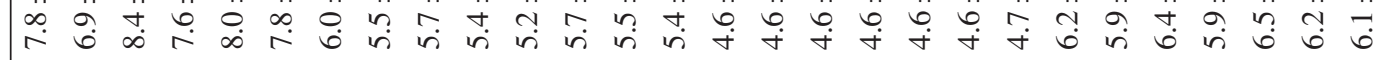

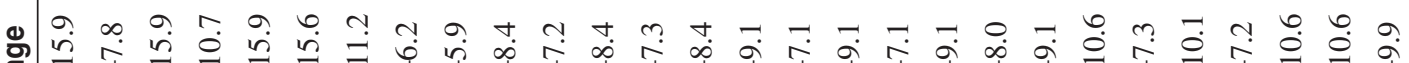
Æ̋

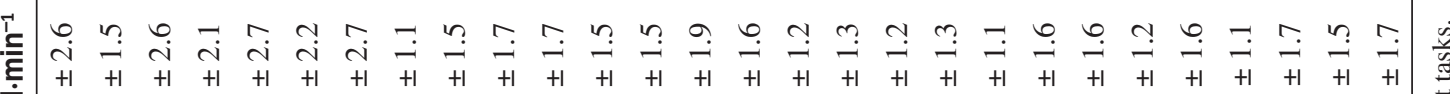
㐫

๑

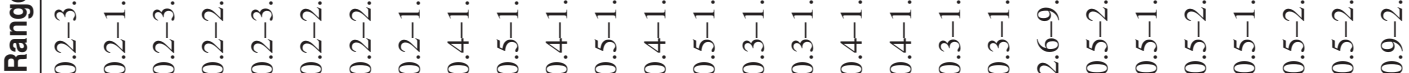

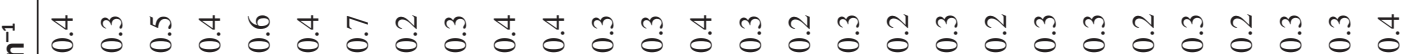

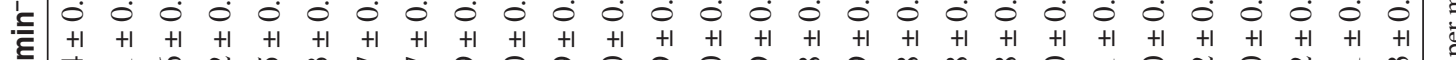

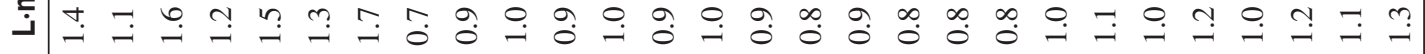

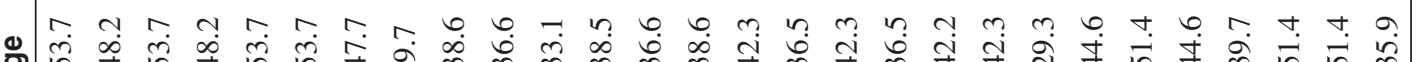

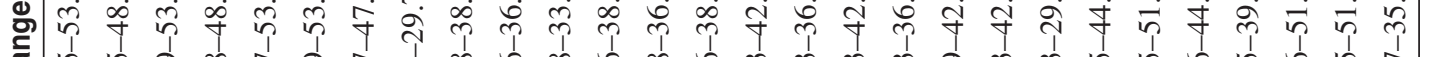

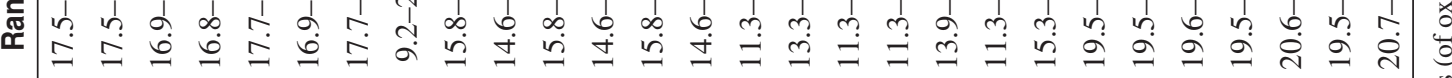

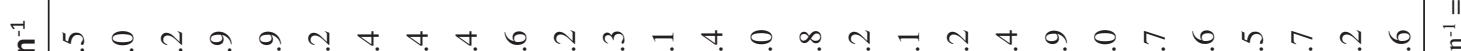

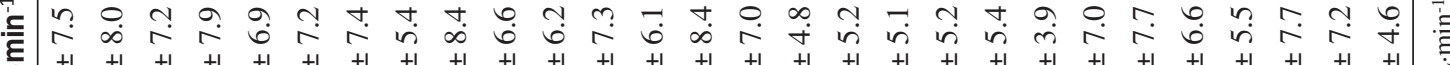

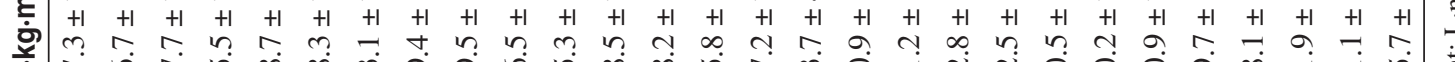

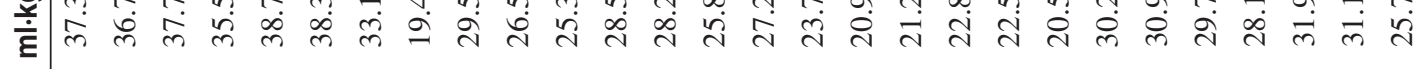

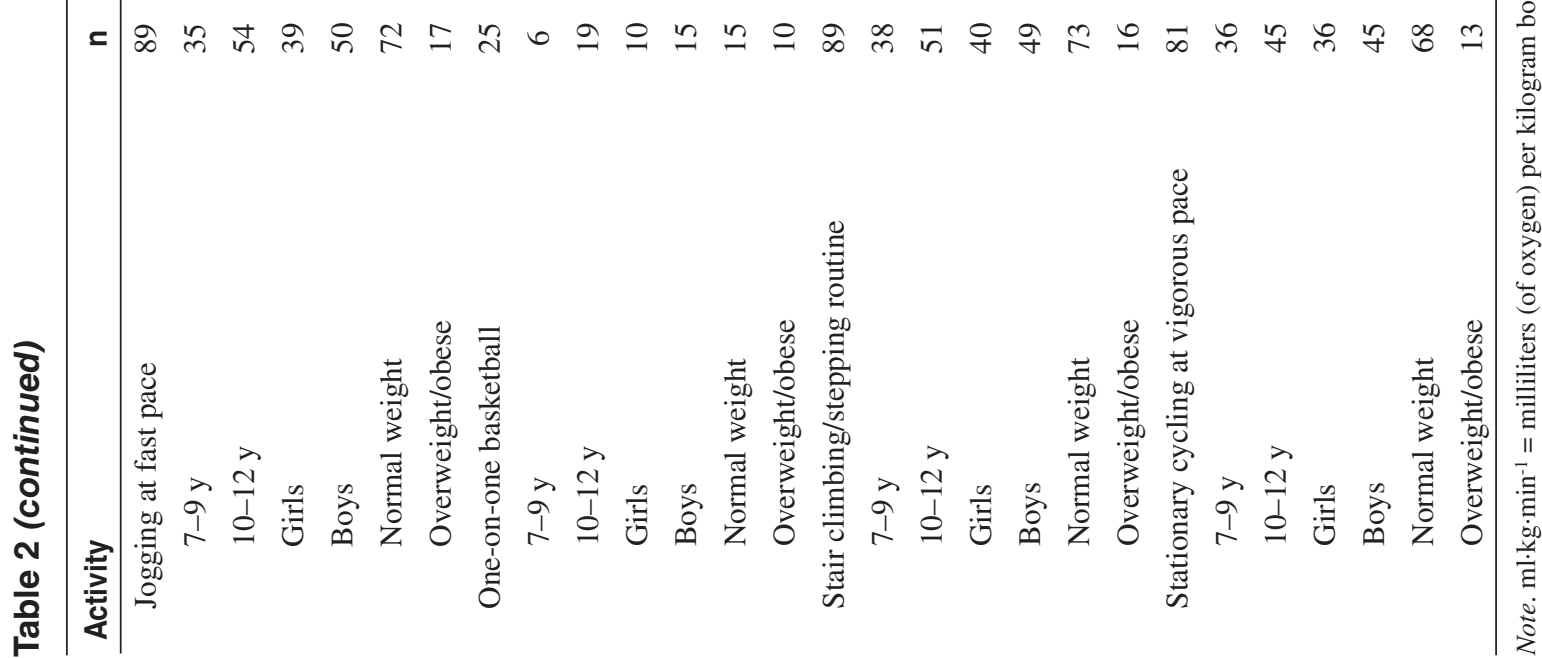


$(P<.01)$. The adjusted means by BMI status resultant from our previous model are provided in Figure 1 (TOP) and can be directly compared with the distribution of METs when using adult-METs. These results indicated that MET values among overweight/obese youth were either similar or consistently lower when compared with normal weight participants. MET values were particularly lower $(P<.01)$ among overweight/obese youth when watching TV (ie, Sedentary), playing a videogame (ie, Sedentary), jogging at fast pace (ie, MVPA), and cycling at a vigorous pace (ie, MVPA), and there were some marginal significant differences in 2 extra activities (ie, light calisthenics and stationary cycling at a moderate pace) (Figure 1, BOTTOM). This finding is consistent with previous literature that has highlighted the confounding effect of body size on REE and the systematic misclassifications of activity intensity in larger children when using adult-METs. ${ }^{5-8}$ Previous literature has demonstrated that EE costs of activities are overestimated in children when expressed in adult-METs. ${ }^{9,10}$ However, we now reinforce the notion that the use of adult-METs also has different implications depending on youth body sizes. This additional confounding is in addition to the effects of age and sex.

Our EE data across a variety of activities in a large sample of children revealed no clear patterns in child-adjusted METs by sex, age, or body size. However, the study demonstrated that there are considerable variations in EE of activities for normal weight and overweight/obese youth when adult MET values (ie, $3.5 \mathrm{ml} \cdot \mathrm{kg} \cdot \mathrm{min}^{-1}$ ) are used in lieu of youth METs. We showed that these patterns were attributable in large part to differences in body size, and this reinforces the importance of the current supplement and use of child-specific MET values

\section{Acknowledgments}

We thank all participants and parents that participated in this investigation. This work was funded by a grant from the National Institutes of Health (R01 HL091006).
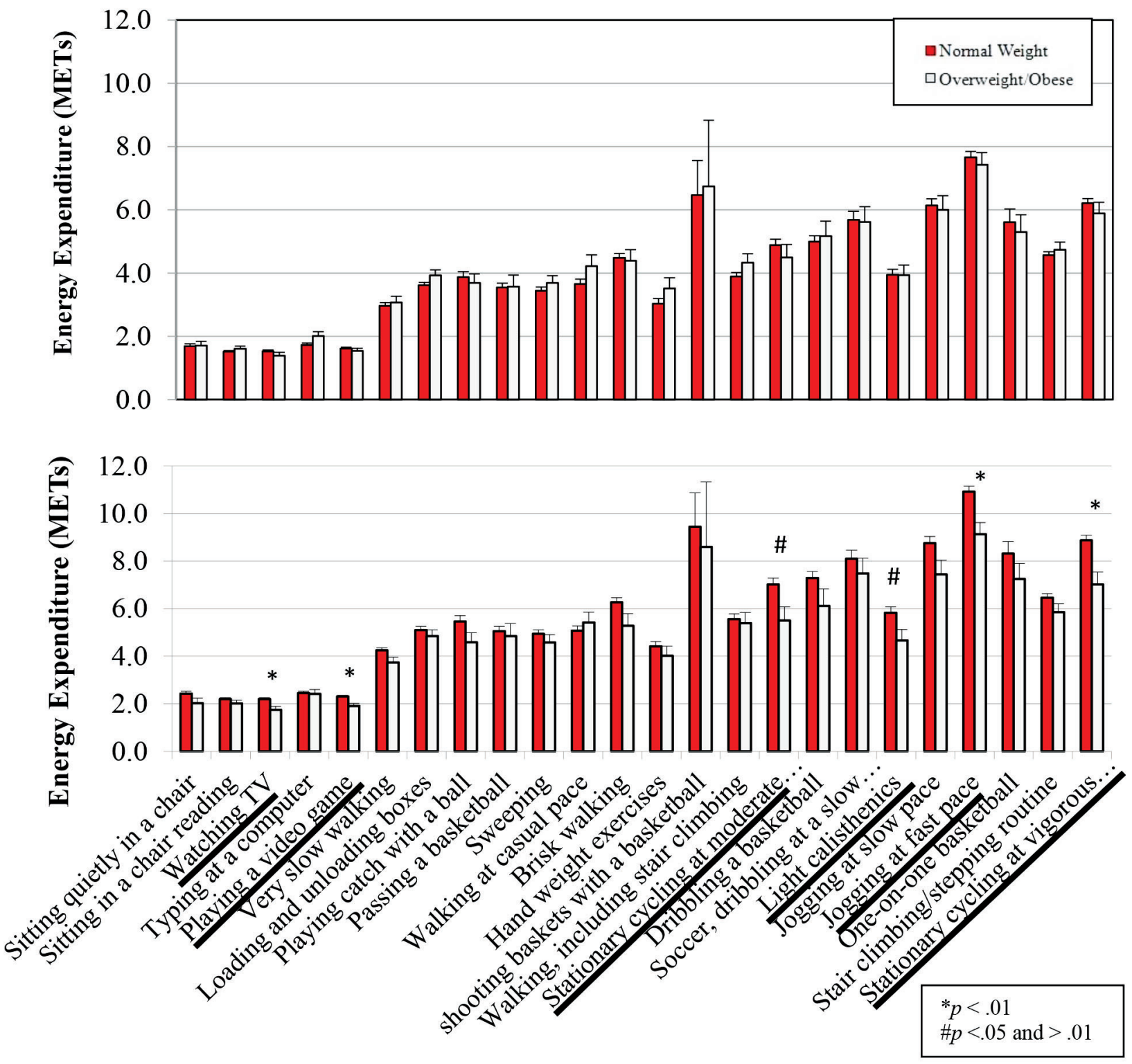

Figure 1 - Distribution of child- (TOP) and adult-derived METs (BOTTOM) for normal weight and overweight/obese children. 


\section{References}

1. Ridley K, Ainsworth BE, Olds TS. Development of a compendium of energy expenditures for youth. Int J Behav Nutr Phys Act. 2008;5(1):45. PubMed doi:10.1186/1479-5868-5-45

2. Schofield W. Predicting basal metabolic rate, new standards and review of previous work. Hum Nutr Clin Nutr. 1985;39:5-41. PubMed

3. Saint-Maurice PF, Kim Y, Welk GJ, Gaesser GA. Kids are not little adults: What MET threshold captures sedentary behavior in children? Eur J Appl Physiol. 2016;116(1):29-38. PubMed

4. Ainsworth BE, Haskell WL, Herrmann SD, et al. 2011 Compendium of Physical Activities: a second update of codes and MET values. Med Sci Sports Exerc. 2011;43(8):1575-1581. PubMed doi:10.1249/ MSS.0b013e31821ece12

5. Byrne NM, Hills AP, Hunter GR, Weinsier RL, Schutz Y. Metabolic equivalent: one size does not fit all. J Appl Physiol (1985). 2005;99(3):1112-1119.
6. Molnar D, Schutz Y. The effect of obesity, age, puberty and gender on resting metabolic rate in children and adolescents. Eur J Pediatr. 1997;156(5):376-381. PubMed doi:10.1007/s004310050618

7. Tompuri TT. Metabolic equivalents of task are confounded by adiposity, which disturbs objective measurement of physical activity. Front Physiol. 2015;6:226. PubMed doi:10.3389/fphys.2015.00226

8. Spadano JL, Must A, Bandini LG, Dallal GE, Dietz WH. Energy cost of physical activities in 12-y-old girls: MET values and the influence of body weight. Int J Obes Relat Metab Disord. 2003;27(12):1528-1533. PubMed doi:10.1038/sj.ijo.0802440

9. Harrell JS, McMurray RG, Baggett CD, Pennell ML, Pearce PF, Bangdiwala SI. Energy costs of physical activities in children and adolescents. Med Sci Sports Exerc. 2005;37(2):329-336. PubMed doi:10.1249/01.MSS.0000153115.33762.3F

10. Ridley K, Olds TS. Assigning energy costs to activities in children: a review and synthesis. Med Sci Sports Exerc. 2008;40(8):1439-1446. PubMed doi:10.1249/MSS.0b013e31817279ef 